\title{
Autonomous Car Parking System with Various Trajectories
}

\author{
Bunyamin Esiyok ${ }^{1}$, Anil Can Turkmen ${ }^{2}$, Ozgur Kaplan $^{2}$, Cenk Celik $^{2}$ \\ ${ }^{1}$ Department of Electrical and Electronics Engineering,Yeditepe University \\ ${ }^{2}$ Department of Mechanics Engineering, Kocaeli University
}

\begin{tabular}{|c|c|}
\hline Article Info & ABSTRACT \\
\hline Article history: & y, an algorithm presents a solution to 4 -wheel-car parking. This \\
\hline $\begin{array}{l}\text { Received May } 30^{\text {th }}, 2017 \\
\text { Revised Aug } 20^{\text {th }}, 2017 \\
\text { Accepted Oct } 18^{\text {th }}, 2017\end{array}$ & $\begin{array}{l}\text { algorithm is suitable for parallel parking between two objects or two cars. } \\
\text { Firstly the system verifies whether enough space. After finding a valid } \\
\text { parking space, system makes the suitable movements for a perfect parking. } \\
\text { This parking operation is tested in a simulation environment using MatLab- } \\
\text { Simulink. }\end{array}$ \\
\hline
\end{tabular}

Keyword:

Autonomous vehicle

Trajectory

Parallel parking

Ultrasonic sensor

Path planning

\section{Corresponding Author:}

Anil Can Turkmen,

Departement of Mechanical Engineering,

Kocaeli University,

Umuttepe Yerleskesi, 41380, Izmit, Kocaeli, Turkey

Email: anilcan.turkmen@hotmail.com

\section{Introduction}

New generation cars have serious developments and automobile brands are in competition. Due to this competition, intelligent driver assistance systems are playing a key role while automotive industry is being more automated. Researches show that finding a solution to parallel parking is one of the most needed improvements for drivers. Becauseparking is a very difficult topic for novice drivers. Especially in crowded cities this problem is getting bigger because number of the car is increasing every day. [1]

The goal of the park assistant system is to help the drivers have more enjoyable and more productive driving experiences. Also another aim is decreasing damages during the parking operation. Parking damages have very bad effect on World's economy. Because countries and insurance companies pays money for simple parking damages and also owners of the cars' sell their cars below its value because of damage history.

System needs ultrasonic sensors that located on the corners of the car. These sensors needed not only for doing parking movements, but also scanning the park area. There are some problems about ultrasonic sensors. For example, thin objects are not seen by this sensors and some environmental changes as temperature, pressure, humidity, air turbulence, airborne particles etc. effect on ultrasonic response. Despite these disadvantages ultrasonic sensors are the most suitable sensor for these systems.

\section{Literature Survey}

In recent years, parking assistance systems were improved in the automotive industry to make perfect movements for perfect parking instead of drivers. Path planning is one of the important problems for parking 
operation. For this reason, trajectory planning algorithm needs to be good and creative for a collision-free path starting from the first point to last position, which is described as parking area. Of course this trajectory needs to satisfy all kinematic conditions and limitations of the car model.This kind of problem belongs to the most frequently considered examples in robotics literature, where various solution approaches are available, e.g. planning based on neural-networks, fuzzy-techniques, dynamic programming, numerical continuation methods and two-step algorithms making use of small-time controllability. In any case, rather experimental techniques are connected for this assignment in application. One reason might be that lots of authors analyzed the case of full autonomous-maneuvering, though most versions of assistant systems just control the steering system of the car, but driver still need to control the velocity. One more issue of the systematic technique is that frequently complicated calculations are included which are difficult to achieve progressively. Besides, some of features required by the automotive industry, like that the path founded by the car should be same as the behavior of a real driver or that steering at standstill should be avoided, are rather difficult to integrate into the systematic-frameworks.

In this contribution, a usable type of an algorithm is developed and this algorithm ensures the requirements for some real-life applications. Besides, the methodology is based on a strong hypothesis guaranteeing that a solution is always found provided that one exists. In principle, the proposed strategy is a combination of the crash-free planned path algorithm created in and the path planner for a vehicle presented in. Parking operation has special requirements such as velocity controlling, steering controlling, trajectory finding etc. These processes have to be in progress together and final position of the vehicle should be where it is demanded. Besides, it is indicated how sensible calculation times can be accomplished by performing real parts of required costly figuring offline. In this setting, some point of interest on a keen usage structure of the algorithm is given. In the following section a suitable dynamic model of a vehicle is presented and the considered trajectory planning issue is defined all the more definitely. Besides, some essential outcomes coming about because of the uncommon structure and basic properties of the vehicle model are expressed. [2]

\subsection{Previous Parking Algorithms}

In 1999, M. Wada, K. Yoon, H. Hashimoto, and S. Matsuda proposed a paper in an International Conference named "Development of advanced parking system using human guidance". This paper offers not only parallel but also vertical parking with an increased complexity in maneuvers and numerous direction changes. In this solution, parking time lasts longer and needs parking space around 1.55 times of the vehicle length for the parking process. [3]

In 2001, F. Gomez-Bravo, F. Cuesta and A. Ollero, proposed a paper named "Parallel and diagonal parking in nonholonomic autonomous vehicles". This study presents collision-free trajectories from initial position to final position. There are several trajectories determined before and the algorithm based on fuzzy logic controller. Researchers tested that method in a small electrically powered car model. But testing with a real car model was unsuccessful because of the less ability of parking the car in small distance areas. Real car kinematics is not appropriate for this method. [4]

In 2008, T.-H. Hsu, J.-F. Liu, P.-N. Yu, W.-S. Lee proposed a paper named "Development of an automatic parking system for vehicle," in Vehicle Power and Propulsion Conference. This paper focuses on steering motor controller. In the project, main idea is parking the car with the path which has the minimum length from the possible trajectories. This parking system just working for the back parking process. [5]

In 2006, I. Song, K. Gowan, J. Nery, H. Han, T. Sheng, H. Li, and F. Karray proposed a paper "Intelligent parking system design using fpga" in an international conference which is also a fuzzy-control based solution. This study concentrates on initial and final positions of the trajectories and does not care about the comfortable drive. But instead of comfortable drive, that study presents fast car parking for the drivers. [6]

In 2000, J. Xu, G. Chen, and M. Xie proposed a vision guided automatic parking paper named "Vision-guided automatic parking for smart car" in Intelligent Vehicles Symposium. In this system video data needed to find a space and calculate a collision-free parking path. Neural network and hybrid fuzzy logic algorithms are used to find solution. This parking operation is useful for parallel parking operation. [7] 
In 2012, N.Scicluna,E.Gatt,O.Casha,I.Grech,andJ.Micallef proposed a paper for autonomous parking using fuzzy logic control in International conference named "Fpga-based autonomous parking of a car-like robot using fuzzy logic control'[8]

After having knowledge about these algorithms, generally systems need parking space more than 1.4 times of the vehicle length for the parking process. [9]

\section{Parking Problem}

Parking is the process that leaving the car temporarily in a parking area until it required. Parking process seems easy but it has some difficulties especially for novice drivers. There are a lot of factors that effect on parking process. For example; length of the car, steering angle, size of the tires, angle of the road etc. Also there is a problem about the parking area, because parking could be between two cars, by the side of the road, or in a parking space between poles etc.There is no standard parking space set in the world. Every countries and local governments have their rules. This problem starts from that not every car has the same length. That's why there is no standard variable for parking. Sometimes it's not easy to park these places even for experienced drivers.

\section{Vehicle Model}

\subsection{Bicycle Model}

Bicycle model is widely used in this kind of research as autonomous systems. This model can be modified to four-wheel car.

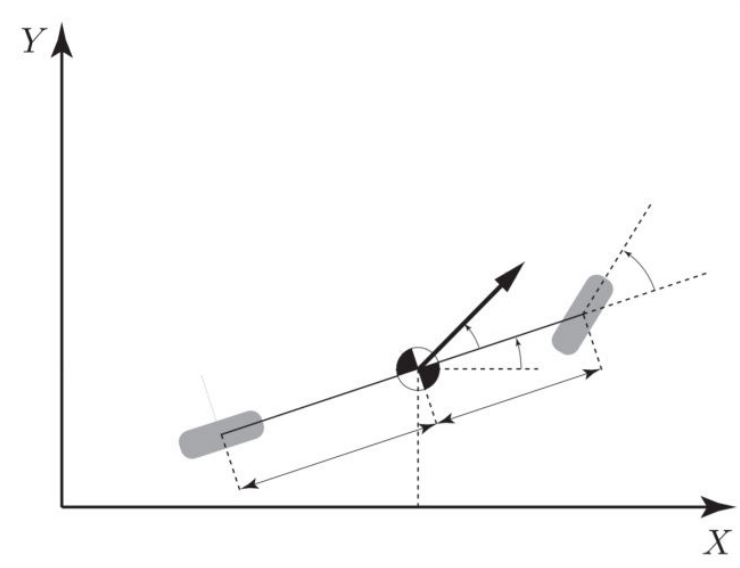

Figure 1. An example of a bicycle model. [10]

Center of gravity is one of the important point for automotive engineering. Bicycle model is flexible and realistic. Any model can be built up to this dynamic. A usable car which has a great load distribution between front and rear wheels is found for this study.

In this study, themodel is consist on the following variables:

Lenght: $4491 \mathrm{~mm}$

Width: $1852 \mathrm{~mm}$

Wheelbase: $2450 \mathrm{~mm}$

Turning circle diameter: $11100 \mathrm{~mm}$ 


\section{Simulations}

In this system, realistic conditions were used as soon as possible. These conditions were entegrated to simulation environment. Assumptions distances were set from parked car to autonomous car as 0.57, 1.416, 2.262 meters and tested successfully in Simulink.

Fig. 2. shows the initial position of the autonomous car. Driver presses the button for autonomous parking at this time. Time is equal to 5 seconds (Fig 3). Car started to search a free space and at that time parking light turned into yellow. That means car found a free space but still searching for the right distance. Also car keeps going at that time.In Fig. 4., time is equal to 11 seconds, parking light turned into red because car did not detect a suitable area for parking. The 35th second of the simulation seems at Fig 5., sensors detected that free space on the right of the car and parking light turned into yellow. Car changed the shift at that time and now gear is " $R$ " and car started to parking.

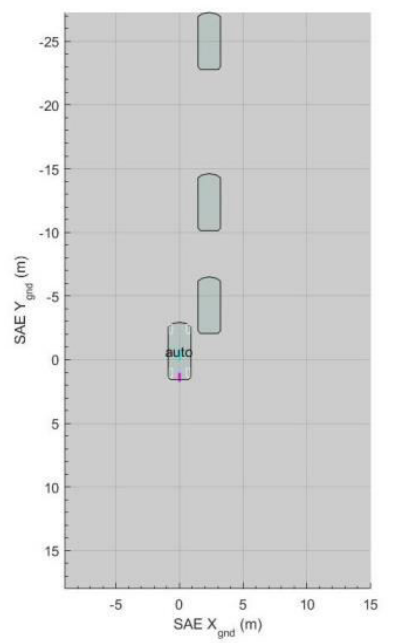

Figure 2. Simulation step 1

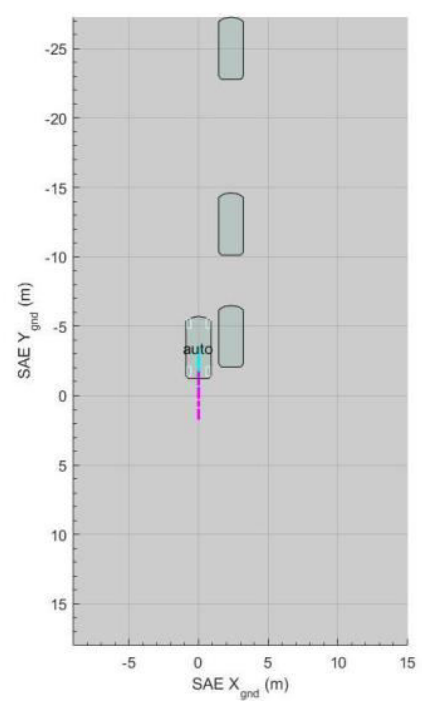

Figure 3. Simulation step 2 


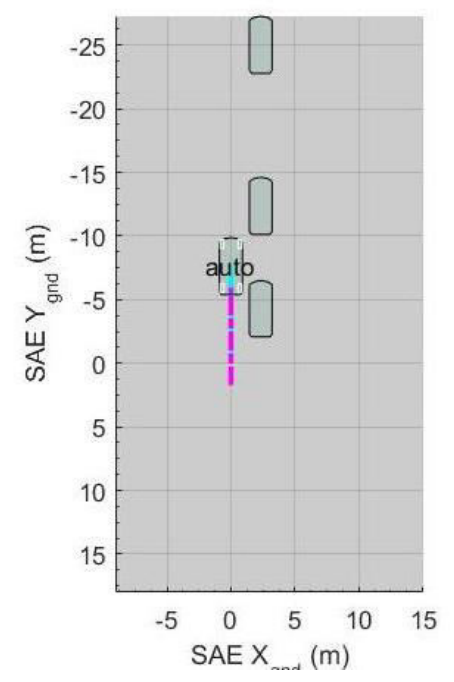

Figure 4. Simulation step 3

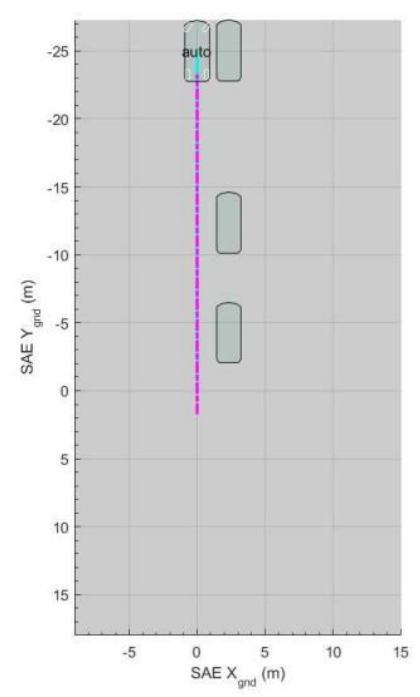

Figure 5. Simulation step 4

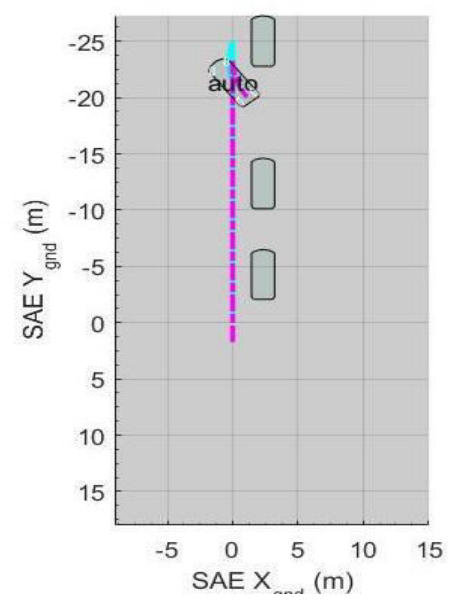

Figure 6. Simulation step 5 


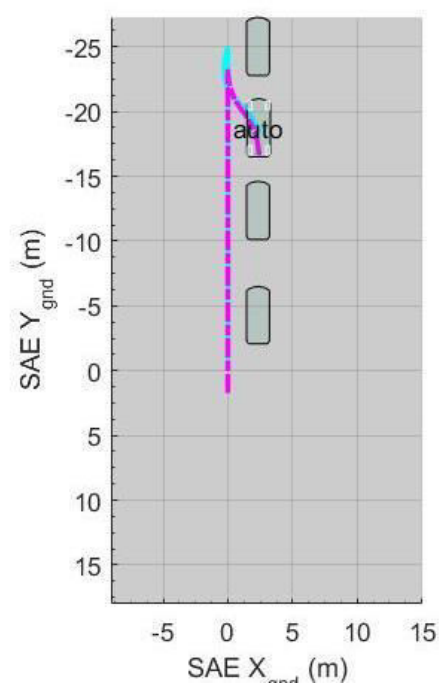

Figure 7. Simulation step 6

Fig. 6 shows the 40th second of the parking process. Now wheels are 40 degrees turned to right side. Car keeps going rear.Car turned the wheel to the left side with 40 degrees and reached to this position in 45th second (Fig. 7). For the final position car goes forward for 1 second and then finishes the process.

In this system, motivation is parking the car with less maneuvering with no crash. Firstly, less maneuvering decreases the fault possibility during parking process. Secondly less maneuvering gives the possibility of parking the car in a shorter time.

\section{Conclusion}

Due to driver does not controlling anything, this system is much more comfortable comparing to other parking assistance systems.System dynamics could be integrated any car model in the future.In the system required parking area is found as 1.6 times of the vehicle length.In the system, required free space for parking area is optimum for a comfortable parking space. Because car can leave the parking area with one move and other cars' drivers do not have any potential problem. Due to less maneuvering, possibility of crashing to a car or an object is less and system reduces the possibility of making mistake.Fuel consumption is directly related to shift. From first to top gear fuel consumption decreases. Also rear shift's consumption is as high as first shift. During parking process first and rear shifts are used. That's why during parking process, car consumes much more fuel. If we decrease the maneuvering move steps, car consumes less. A regular driver parks the car about 600 times during the whole year. But there are numerous drivers that work with car and park it more than 5 times during a day. This means less maneuvered car parking systems saves money and contributes the economy.

\section{References}

[1] M. U. Rafique, K. Faraz, "Guidance Based Autonomous Parking Assistant", $2^{\text {nd }}$ International Conference on Industrial Mechatronics and Automation, Wuhan-China, 30 May-31 May2010, pp. 320-324,China, 2010.

[2] B. Muller, J. Deutscher, S. Grodde, "Continuous Curvature Trajectory Design and Feedforward Control for Parking a Car", IEEE Transactions on Control Systems Technology, Vol. 15, No.3, May 2007,pp. 541-553.

[3] M. Wada, K. Yoon, H. Hashimoto, S. Matsuda, "Development of advanced parking assistance system using human guidance," in Advanced Intelligent Mechatronics, 1999. Proceedings. 1999 IEEE/ASME International Conference on, 1999, pp. 997-1002.

[4] F. Gomez-Bravo, F. Cuesta, A. Ollero, "Parallel and diagonal parking in nonholonomic autonomous vehicles," Engineering Applications of Artificial Intelligence, vol. 14, no. 4, pp. 419 - 434, 2001. 
[5] T.-H. Hsu, J.-F. Liu, P.-N. Yu, W.-S. Lee, J.-S. Hsu, "Development of an automatic parking system for vehicle," in Vehicle Power and Propulsion Conference, 2008. VPPC '08. IEEE, 2008, pp. 1-6.

[6] I. Song, K. Gowan, J. Nery, H. Han, T. Sheng, H. Li, F. Karray, "Intelligent parking system design using fpga," in Field Programmable Logic and Applications, 2006. FPL '06. International Conference on, 2006, pp. 1-6.

[7] J. Xu, G. Chen, M. Xie, "Vision-guided automatic parking for smart car," in Intelligent Vehicles Symposium, 2000. IV 2000. Proceedings of the IEEE, 2000, pp. 725-730.

[8] N.Scicluna,E.Gatt,O.Casha,I.Grech,J.Micallef,"Fpga-basedautonomousparking of a car-like robot using fuzzy logic control," in Electronics, Circuits and Systems (ICECS), 2012 19th IEEE International Conference on, 2012, pp. 229-232.

[9] H. Ertugrul, "An FPGA Implementation of two-step Trajectory Planning for Automatic Parking”, Middle East Technical University, Sept 2013, pp. 6-7.

[10] R. Rajamani, Vehicle Dynamics and Control, ser. Mechanical Engineering Series. Springer, 2011 pp. 26. 